\title{
Peripartum cardiomyopathy
}

\author{
Lori A Blauwet $\mathrm{MD}^{\star}$ and Karen Sliwa $\mathrm{MD} \mathrm{PhD}^{\dagger}$
}

*Division of Cardiovascular Diseases, Mayo Clinic, Rochester, MN, USA; ${ }^{\dagger}$ Hatter Cardiovascular Research Institute, Department of Medicine, Faculty of Health Sciences, University of Cape Town, Cape Town, South Africa

\begin{abstract}
Summary: Peripartum cardiomyopathy (PPCM) is a potentially devastating disease that affects women during the last months of pregnancy or the first months after delivery. The aetiology and pathogenesis of this disease remain unclear, but oxidative stress and the generation of a cardiotoxic fragment of prolactin may play key roles. Diagnosing PPCM remains a challenge, as symptoms may mimic those women experience during normal pregnancy and the peripartum period. A high index of suspicion is thus necessary to make the diagnosis. Patients with PPCM have a varied clinical course, as some patients achieve full recovery while others progress to end-stage heart failure and even death. Standard heart failure treatment is indicated, although special provisions are necessary in pregnant and lactating women. Additional research into the pathophysiology of this disease, including possible genetic contributions, may lead to novel treatment strategies that can improve outcomes.
\end{abstract}

Keywords: PPCM, cardiomyopathy, pregnancy, heart failure

\section{INTRODUCTION}

Peripartum cardiomyopathy (PPCM) is one of several causes of pregnancy-related heart failure. Although various aetiologies have been proposed, the reason why some women develop this disease either during the last months of pregnancy or within the first few months postpartum remains unclear. Oxidative stress and the generation of a cardiotoxic fragment of prolactin may play key roles in the pathogenesis of PPCM. The diagnosis is one of exclusion and is made on clinical presentation and non-invasive imaging. The clinical course of patients with PPCM is highly variable. Some patients rapidly progress to end-stage heart failure, while a significant percentage of patients with PPCM spontaneously recover normal cardiac function. The aim of this review is to provide a concise and practical approach to the diagnosis and treatment of suspected PPCM.

\section{DEFINITION}

Although heart failure in pregnancy has been recognized since the 19th century, diagnostic criteria for PPCM as a specific disease entity were first proposed by Demakis and colleagues in $1971^{1}$ and confirmed by a workshop held by the National Heart, Lung, and Blood Institute and the Office of Rare Diseases in 2000. ${ }^{2}$ Alternative definitions have subsequently been proposed by other groups, most recently by the Heart Failure Association of the European Society of Cardiology Working Group on PPCM earlier this year (Table 1). ${ }^{3}$ These

Correspondence to: Lori A Blauwet, Division of Cardiovascular Diseases, Mayo Clinic, 200 First Street SW, Rochester, MN 55905, USA

Email: blauwet.lori@mayo.edu various classifications emphasize that PPCM is a relatively rare idiopathic form of heart failure with left ventricular (LV) systolic dysfunction associated with pregnancy.

\section{EPIDEMIOLOGY}

The true incidence of PPCM has been difficult to determine because clinical presentations vary widely and current estimates are largely based on case series from single centres in the USA, South Africa and Haiti. Incidence varies between geographic regions and is reported to range from one in 2500-5500 deliveries in the USA to one in 300 in Haiti (Table 2). ${ }^{4-11}$

\section{AETIOLOGY AND PATHOPHYSIOLOGICAL MECHANISMS}

Although a variety of aetiologies and pathogenic mechanisms have been proposed, the precise cause and mechanism that leads to PPCM remains unclear.

\section{Risk factors}

Factors that determine susceptibility to PPCM are not fully known, although a variety of factors have been implicated (Figure 1). Genetic factors may play a role (see below). Being of African descent has been associated with increased risk for developing PPCM, but this is probably confounded by ethnic and socioeconomic factors. ${ }^{24}$

\section{Inflammatory}

Myocarditis was first proposed as the cause for PPCM nearly three decades ago. Melvin and colleagues ${ }^{25}$ reported three 
Table 1 Definition of peripartum cardiomyopathy

\begin{tabular}{|c|c|c|}
\hline Source & Year & Definition \\
\hline Demakis et al. ${ }^{1}$ & 1971 & $\begin{array}{l}\text { Development of cardiac } \\
\text { failure in the last month of } \\
\text { pregnancy or within five } \\
\text { months of delivery } \\
\text { Absence of a determinable } \\
\text { aetiology for the cardiac } \\
\text { failure } \\
\text { Absence of demonstrable } \\
\text { heart disease prior to the last } \\
\text { month of pregnancy }\end{array}$ \\
\hline $\begin{array}{l}\text { Workshop held by the National } \\
\text { Heart, Lung, and Blood Institute } \\
\text { and the Office of Rare Diseases } \\
\text { of the National Institutes of } \\
\text { Health Workshop on Peripartum } \\
\text { Cardiomyopathy }\end{array}$ & 2000 & $\begin{array}{l}\text { Development of cardiac } \\
\text { failure in the last month of } \\
\text { pregnancy or within five } \\
\text { months of delivery } \\
\text { Absence of an identifiable } \\
\text { cause for the cardiac failure } \\
\text { Absence of recognizable } \\
\text { heart disease prior to the last } \\
\text { month of pregnancy } \\
\text { LV systolic dysfunction } \\
\text { demonstrated by classical } \\
\text { echocardiographic criteria: } \\
\text { ejection fraction }<45 \% \text { or } \\
\text { fractional shortening }<30 \% \text {, } \\
\text { or both }\end{array}$ \\
\hline $\begin{array}{l}\text { American Heart Association } \\
\text { Scientific Statement on } \\
\text { contemporary definitions and } \\
\text { classifications of the } \\
\text { cardiomyopathies }^{63}\end{array}$ & 2006 & $\begin{array}{l}\text { Peripartum (postpartum) } \\
\text { cardiomyopathy is a rare and } \\
\text { dilated form associated with } \\
\text { LV systolic dysfunction and } \\
\text { heart failure of unknown } \\
\text { cause that manifests } \\
\text { clinically in the third trimester } \\
\text { of pregnancy or the first five } \\
\text { months postpartum and } \\
\text { requires a high index of } \\
\text { suspicion for diagnosis }\end{array}$ \\
\hline $\begin{array}{l}\text { Heart Failure Association of the } \\
\text { European Society of Cardiology } \\
\text { Working Group on PPCM } 2010^{3}\end{array}$ & 2010 & $\begin{array}{l}\text { PPCM is an idiopathic } \\
\text { cardiomyopathy presenting } \\
\text { with heart failure secondary } \\
\text { to LV systolic dysfunction } \\
\text { towards the end of } \\
\text { pregnancy or in the months } \\
\text { following delivery, where no } \\
\text { other cause of heart failure is } \\
\text { found. It is a diagnosis of } \\
\text { exclusion. The left ventricle } \\
\text { may not be dilated but the } \\
\text { ejection fraction is nearly } \\
\text { always reduced below } 45 \%\end{array}$ \\
\hline
\end{tabular}

$\mathrm{LV}=$ left ventricular; PPCM = peripartum cardiomyopathy

Adapted from Sliwa et al., ${ }^{3}$ with permission

cases of PPCM due to myocarditis based on histological findings including inflammatory infiltrate, oedema, fibrosis and necrosis seen in right ventricular biopsy specimens. Treatment with immunosuppression resulted in clinical improvement and resolution of inflammatory infiltrates in follow-up EMB specimens in all three patients. Subsequent EMB studies by Sanderson et al. ${ }^{26}$ and O'Connell et al. ${ }^{27}$ found histological evidence consistent with myocarditis in $45 \%$ and $29 \%$ of PPCM patients, respectively. In the 1990s, Midei and colleagues ${ }^{28}$ reported that $14(78 \%)$ of 18 PPCM patients had histological findings suggestive of myocarditis, while Rizeq and colleagues $^{29}$ found that only $3(9 \%)$ of the 45 PPCM patients had similar findings. A few years later, an EMB study by Felker and colleagues ${ }^{30}$ showed a $62 \%$ prevalence of myocarditis in
Table 2 Incidence of peripartum cardiomyopathy

\begin{tabular}{|c|c|c|c|c|c|}
\hline Author & Year & Study design & Country & $\begin{array}{l}\text { Number of } \\
\text { patients }\end{array}$ & Incidence \\
\hline Kuklina $^{4}$ & 2010 & $\begin{array}{c}\text { Population } \\
\text { based }\end{array}$ & USA & 2578 & $1: 5556$ \\
\hline Brar $^{6}$ & 2007 & $\begin{array}{c}\text { Population } \\
\text { based }\end{array}$ & USA & 60 & $1: 4025$ \\
\hline Mielniczuk $^{5}$ & 2006 & $\begin{array}{c}\text { Population } \\
\text { based }\end{array}$ & USA & 171 & $1: 3189$ \\
\hline Chapa $^{7}$ & 2005 & Case series & USA & 32 & $1: 1149$ \\
\hline Witlin 8 & 1997 & Case series & USA & 28 & $1: 2406$ \\
\hline Pandit $^{9}$ & 2009 & Case series & India & 9 & $1: 1374$ \\
\hline Desai $^{14}$ & 1995 & Case series & $\begin{array}{l}\text { South } \\
\text { Africa }\end{array}$ & 97 & $1: 1000$ \\
\hline Hasan $^{10}$ & 2010 & Case series & Pakistan & 32 & $1: 837$ \\
\hline Fett $^{11}$ & 2005 & Case series & Haiti & 98 & $1: 300$ \\
\hline
\end{tabular}

Adapted from Sliwa et al., ${ }^{3}$ with permission

PPCM patients. The presence or absence of myocarditis had no impact on survival in that study.

Given the results of the EMB studies cited, it is clear that the reported prevalence of myocarditis in PPCM is highly variable. This is probably due to a combination of factors including differing study inclusion criteria based on varying definitions of PPCM, variability in timing between clinical presentation and EMB biopsy, and sampling error. Despite these findings from multiple EMB studies which suggest an association between myocarditis and PPCM, no causal relationship has been established to date.

\section{Infections}

Viral infection is a common cause of myocarditis and it has been proposed that it may also cause PPCM. In one study, EMB specimens from nearly one-third of PPCM patients revealed molecular evidence of viral genomic material with

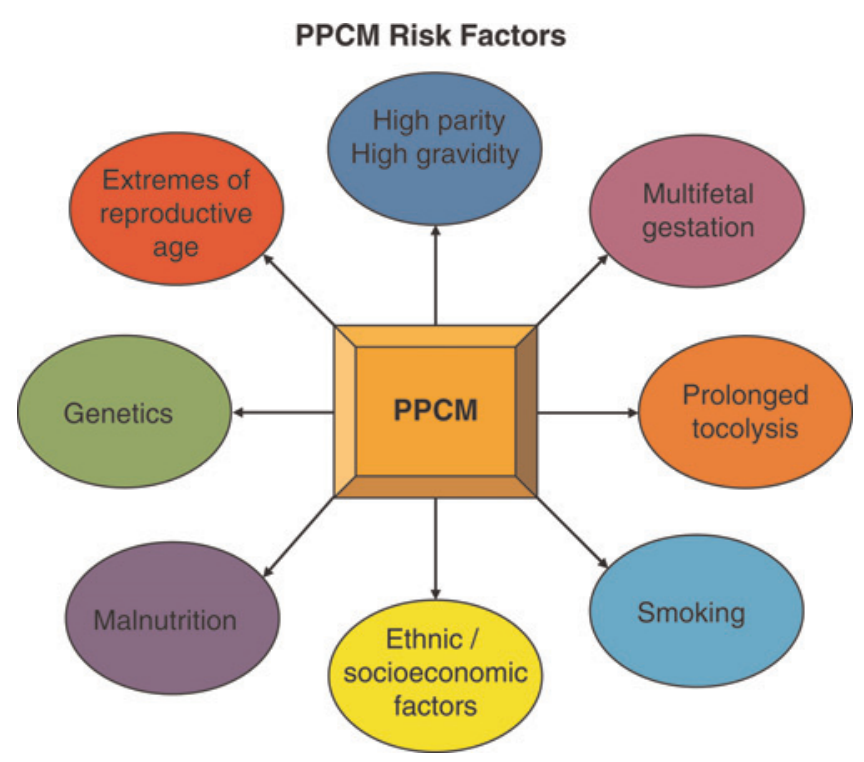

Figure 1 Proposed risk factors for PPCM include numerous clinical, ethnic, socioeconomic and genetic factors. PPCM = peripartum cardiomyopathy 
associated inflammatory changes. ${ }^{31}$ It has also been shown that viral genomic material can be found in EMB specimens from patients with idiopathic DCM and that viral clearing results in clinical improvement. ${ }^{32}$ Further investigation into whether or not similar results can be found in patients with PPCM is warranted.

\section{Abnormal immune response to pregnancy}

Another hypothesis purports that immune activation contributes to the development of PPCM. Sliwa and colleagues ${ }^{17,33}$ established that increased concentrations of cytokines including tumour necrosis factor $\alpha$, IL1 and IL6 were present in a large number of recently diagnosed PPCM patients. Levels of Fas/ Apo-1, a plasma marker of apoptosis, were considerably higher than in healthy controls and were predictive of mortality.

Ansari and colleagues ${ }^{34}$ have suggested that fetal microchimerism (the presence of fetal cells in the maternal circulation during and after pregnancy) may trigger an exaggerated autoimmune response in patients with PPCM. They found that PPCM patients had elevated plasma levels of male chromosomal DNA during the third trimester of pregnancy, at term, and in the first week postpartum compared with healthy controls. Increased numbers of fetal cells may initiate an autoimmune response, possibly resulting in autoimmune myocarditis.

Other studies have suggested that PPCM may be caused by an autoimmune process triggered by autoantibodies produced during delivery. Rapid degeneration of the uterus after delivery causes fragmentation of tropocollagen resulting in release of actin, myosin and various other proteins into the maternal circulation. Antibodies formed against actin and some of these other proteins may cross-react with similar proteins in the myocardium. Autoantibodies to numerous cardiac antigens are common in patients with $\mathrm{PPCM}^{2}$ but whether or not they play a role in the pathogenesis of PPCM remains to be investigated.

\section{Prolactin, $16 \mathrm{kDa}$ prolactin and cathepsin D}

The most recent hypothesis proposed suggests that oxidative stress, the prolactin-cleaving protease cathepsin D and prolactin itself may be implicated in the pathogenesis of PPCM. Oxidative stress seems to lead to activation of cathepsin D, which cleaves prolactin into the proapoptotic, angiostatic fragment $16 \mathrm{kDa}^{35}$ A mouse model has demonstrated that the $16 \mathrm{kDa}$ prolactin fragment inhibits endothelial cell proliferation and migration, induces endothelial cell apoptosis, disrupts capillary structures, promotes vasoconstriction and impairs cardiomyocyte function. ${ }^{35}$

As cellular markers of oxidative stress rise during normal pregnancy, particularly during the last trimester, ${ }^{36}$ adequate antioxidant defence mechanisms are necessary. Hilfiker-Kleiner et al. ${ }^{35}$ have developed a mouse model of PPCM, showing that the cardiomyocyte-restricted deletion of STAT-3, the signal transducer and activator of transcription-3, results in the development of PPCM in female mice. In support of the key role that the oxidative stress-cathepsin $\mathrm{D}-16 \mathrm{kDa}$ prolactin cascade plays in PPCM, it has been shown that the suppression of prolactin production by administration of bromocriptine prevented the onset of PPCM in these mice. A pilot study of the use of bromocriptine in acute PPCM has produced encouraging results, ${ }^{37}$ but these need to be confirmed in a larger randomized controlled trial.

\section{Genetic susceptibility}

Systematic studies of the genetic contribution to susceptibility for PPCM have not yet been performed. Several case reports have noted that some women with PPCM have mothers or sisters who have also had this disease. ${ }^{38-42}$ These reports have raised the question as to whether these cases are truly familial PPCM or perhaps instead represent familial DCM unmasked by the haemodynamic stress of pregnancy.

Two recent studies have suggested that some cases of PPCM may be part of a spectrum of familial DCM and that genetic mutations associated with DCM may be implicated in its pathogenesis. ${ }^{43,44}$ Although these studies were retrospective and data were available for only a small number of cases, the results are intriguing and further research is warranted.

\section{CLINICAL PRESENTATION \\ Symptoms}

The most common presentation of PPCM is that of systolic heart failure. Symptoms are highly variable but may include fatigue, dyspnoea, orthopnoea, paroxysmal nocturnal dyspnoea, persistent cough, peripheral oedema, palpitations, chest pain, decreased exercise tolerance and abdominal discomfort due to passive congestion of the liver.

\section{Signs}

Signs of PPCM include tachypnoea, tachycardia, jugular venous distension, gallop rhythm, lateral and/or downward displacement of the point of maximal impulse, hepatomegaly, hepatojugular reflux and ascites. Blood pressure is usually normal. Rarely, sudden cardiac death is the first recognized manifestation of the disease. Early signs and symptoms of PPCM may mimic normal physiological findings of pregnancy and the postpartum period.

\section{Timing}

Most women with PPCM develop symptoms within the first few months following delivery rather than during pregnancy. Fatigue, a commonly reported symptom, may be attributed to recent delivery, the associated lack of sleep or anaemia, thus delaying diagnosis. Early diagnosis is important, as delayed diagnosis has been associated with increased morbidity and mortality. $^{12}$

\section{NATURAL HISTORY}

Patients with PPCM have a highly variable clinical course. Unlike most forms of non-ischaemic cardiomyopathy, patients with PPCM may experience rapid progression to end-stage heart failure and death. Alternatively, resolution of symptoms and spontaneous recovery of cardiac function is relatively common.

Intracardiac thrombus may develop, particularly in patients with severely decreased left ventricular ejection fraction (LVEF) with subsequent risk of thromboembolism. Thrombus 
may embolize to any part of the body, potentially resulting in stroke, acute myocardial infarction, mesenteric ischaemia or infarction, lower extremity ischaemia, and pulmonary embolism. The risk of thromboembolic events is particularly increased in patients who are diagnosed with PPCM during pregnancy, as pregnancy and the postpartum period are hypercoagulable states.

Ventricular arrhythmias have been reported in up to $20 \%$ of patients with PPCM. ${ }^{13}$ Although no data on the outcome of these arrhythmias have been published, it is likely that the frequency of ventricular arrhythmias decreases or even resolves with recovery of LV function. Sudden death, presumably from ventricular arrhythmia, has been reported in patients with PPCM during both the acute and chronic stage. Sudden death among PPCM patients with completely normalized LV function has been reported as well, indicating that the risk of sudden cardiac death due to ventricular arrhythmias in patients with PPCM may persist well into recovery.

\section{DIAGNOSIS}

Peripartum cardiomyopathy is considered to be a diagnosis of exclusion. A thorough evaluation is necessary in order to exclude other potential cardiac and non-cardiac aetiologies for heart failure.

\section{Electrocardiogram}

Although widely used as a screening tool, there are no ECG findings that are specific for PPCM. The most common presentation is sinus rhythm with non-specific ST-segment and T-wave abnormalities. ${ }^{14}$ Voltage criteria for LV hypertrophy are frequently present. New onset supraventricular or ventricular arrhythmias may occur, ${ }^{13}$ but rarely cause haemodynamic compromise. Atrioventricular conduction abnormalities are uncommon. Left bundle branch block develops in up to $50 \%$ of cases ${ }^{15}$ and, based on studies on long-term outcomes in patients with systolic heart failure, may serve as a predictor for mortality. ${ }^{16}$

\section{Laboratory}

Non-specific serum markers of inflammation, such as C-reactive protein and leukocyte count, are often elevated. Haemoglobin is frequently decreased. C-reactive protein level on presentation has been shown to correlate positively with LV end-diastolic and end-systolic dimensions and inversely with LVEF, while elevated levels of Fas/Apo-1, a marker of cardiac myocyte apoptosis, is a predictor of mortality. ${ }^{17}$

Patients with PPCM frequently have an elevated serum level of brain natriuretic peptide (BNP) or N-terminal pro-BNP (NTproBNP). ${ }^{18}$ High NT-proBNP levels at baseline are associated with poor outcome at six months, suggesting that these biomarkers may be used for risk stratification in patients with PPCM.

\section{Chest X-ray}

Chest X-ray may show cardiomegaly due to LV enlargement, pericardial effusion or both. Additional findings may include interstitial infiltrates, pulmonary venous congestion and pleural effusion.

\section{Echocardiography}

Cardiac imaging is essential to establish the diagnosis and can provide important prognostic information if PPCM is suspected. Echocardiography is readily available and frequently used for evaluating cardiac chamber size, wall thickness, systolic and diastolic function, mitral regurgitation, and the presence of intracavitary thrombi.

There are no specific echocardiographic features of PPCM, although LV dilation is common. By definition, LV systolic function must be reduced, usually below $45 \%$. Generalized LV hypokinesis is often present, while segmental wall motion abnormalities are rare. Diastolic function is abnormal in most patients, with a restrictive filling pattern frequently present. Right ventricular dysfunction is relatively uncommon but may portend a worse prognosis as has been observed in patients with myocarditis. ${ }^{19}$ Functional mitral valve regurgitation, sometimes severe, is often observed. Ventricular thrombi may be present, particularly in patients with an LVEF $<35 \%$.

\section{Cardiac magnetic resonance imaging}

Cardiac magnetic resonance imaging (MRI) has become a useful tool in evaluating patients with PPCM. Compared with echocardiography, cardiac MRI can more accurately assess chamber volumes and systolic function and has a higher sensitivity for detection of LV thrombus. ${ }^{20}$ In addition, cardiac MRI can evaluate markers of tissue injury including intracellular and interstitial injury, hyperaemia, capillary leakage, necrosis and fibrosis. ${ }^{21}$ Administration of Gadolinium during pregnancy is not recommended, but is acceptable in lactating women.

\section{Endomyocardial biopsy}

Endomyocardial biopsy (EMB) is sometimes performed in patients with suspected PPCM. As no histological classification for the diagnosis of PPCM has been established, the role of $\mathrm{EMB}$ in these patients remains unclear. In selected patients, EMB may be beneficial in establishing the diagnosis and guiding treatment. In such cases, EMB should be performed at a medical centre with a special expertise in this procedure because even though the complication rate is low, death may occur. $^{22}$

\section{Diagnosis of exclusion}

Clinical history, physical examination, and laboratory and test results must be carefully evaluated in order to ascertain that there is no other cause of heart failure in patients suspected to have PPCM. The differential diagnosis in these patients includes pre-existing conditions such as idiopathic dilated cardiomyopathy (DCM), familial DCM, HIV/AIDS cardiomyopathy, valvular heart disease and unrecognized congenital heart disease. Other conditions which may lead to a similar presentation include hypertensive heart disease, pregnancyassociated myocardial infarction and pulmonary embolus.

It is particularly important to exclude pregnancy-induced hypertension (preeclampsia), as the aetiology, treatment and prognosis differ. Unfortunately, inclusion criteria for studies of patients with PPCM have differed such that some studies have included women with preeclampsia, leading to discrepancies in the reported characteristics of these patients as well as 
the timing of presentation. Studies with a greater proportion of patients with preeclampsia report a higher frequency of PPCM cases presenting within the last month of pregnancy, $7,8,23$ while those studies that have included few, if any, patients with preeclampsia report that the majority of patients present in the postpartum period. ${ }^{11,17}$

\section{TREATMENT}

Treatment for patients with PPCM is similar to that for patients with systolic heart failure due to other aetiologies, with two notable exceptions. If PPCM is diagnosed during pregnancy, consideration must be given to the fetus. In PPCM patients treated after delivery, infant care issues such as breastfeeding must be taken into account.

\section{Initial management}

Patients presenting with acute heart failure symptoms require prompt treatment including administration of supplemental oxygen and non-invasive ventilatory support, if needed. Intravenous diuretics should be administered to patients with evidence of congestion and volume overload. Intravenous nitrates may be beneficial in patients with high filling pressures. Patients with a low output state and those with congestion which persists despite administration of diuretics and vasodilators may require inotropic support.

\section{Mechanical circulatory support and transplantation}

Temporary mechanical circulatory support may be effective in patients presenting with circulatory shock. For patients who deteriorate despite optimal medical treatment, implantation of a left ventricular assist device (LVAD) should be considered. Since LVEF normalizes within six months postpartum in a significant percentage of patients with PPCM, an LVAD may be useful either as bridge to transplantation or to recovery. Although several case reports have been published, systematic data on the use of LVADs in patients with PPCM are lacking. Cardiac transplantation, where available, is reserved for those patients who are refractory to optimal medical therapy and mechanical circulatory support. Two small series have shown that outcomes in patients with PPCM are comparable to patients with heart failure due to other aetiologies. ${ }^{45}$

\section{Chronic heart failure management}

\section{Postpartum}

Standard heart failure therapy aimed at decreasing preload and afterload and increasing contractility is recommended. Specific medications include diuretics, angiotensin converting enzyme (ACE)-inhibitors or angiotensin receptor blockers (ARBs), and the introduction of $\beta$-blockers once the patient has stabilized is indicated in patients presenting with PPCM in the postpartum period. The addition of a vasoselective calcium channel blocker such as amlodipine can be considered for greater afterload reduction. Treatment with digitalis and aldosterone antagonists may also be effective and pose minimal risk to infants when used during breastfeeding. Due to the high incidence of thromboembolism in these patients, anticoagulation is recommended in patients with an LVEF $<35 \%$.

\section{Antepartum}

Diuretics should be used with caution as they can theoretically cause decreased placental blood flow. ACE inhibitors and ARBs must be avoided due to their adverse effects on fetal renal function. The combination of hydralazine and nitrates may be used in place of an ACE inhibitor/ARB to provide afterload reduction. Beta blockers may be administered on a short-term basis, as only long-term use has been associated with fetal bradycardia and low birth weight babies. Treatment with $\beta-1$ beta selective blockers is preferred, as $\beta-2$ blockade can theoretically have an antitocolytic effect. The effects of vasoselective calcium channel blockers have not been studied in pregnant women. Digoxin is safe for use during pregnancy and breastfeeding, but requires careful monitoring to avoid complications from excess serum concentrations. The aldosterone antagonists spironolactone and eplerenone should be avoided due to their potential antiandrogenic effects on the fetus. Unfractionated and low molecular weight heparin are preferred for anticoagulation in patients with a low LVEF. The potential teratogenic effects of warfarin need to be carefully considered prior to initiation.

\section{Immunosuppressive treatment}

There are limited data on the use of immunosuppression to treat patients with PPCM. In one study, three PPCM patients diagnosed with biopsy-proven myocarditis demonstrated clinical improvement and decreased signs of inflammation on subsequent cardiac biopsies after treatment with azathioprine and prednisone. ${ }^{25}$ Several studies of patients with virusnegative chronic idiopathic DCM that persists despite optimal medial therapy have shown that use of azathioprine and prednisone results in significant improvement in LVEF and New York Heart Association class. ${ }^{46-48}$ Whether these results apply to patients with PPCM, particularly those whose LV function does not normalize, remains to be studied.

\section{Immunomodulatory treatment}

As inflammation has been implicated in the pathogenesis of PPCM, immunomodulatory therapy may be beneficial. One small prospective study of PPCM patients treated with pentoxifylline in addition to standard heart failure therapy showed significant clinical improvement in these patients compared with controls. ${ }^{49}$

Treatment with intravenous immunoglobulin (IVIG) has been considered, but not prospectively studied. A retrospective study of six PPCM patients showed that treatment with IVIG resulted in a significantly greater increase in LVEF compared with those treated with standard therapy. ${ }^{50}$ More recently, it has been reported that two women with PPCM who had elevated serum antibody titres to influenza virus completely recovered after being treated with IVIG. ${ }^{51}$ Other immunomodulatory therapies such as apheresis and treatment with monoclonal antibodies are intriguing, but have not been studied in PPCM patients.

\section{Antiviral therapy}

As viral infection is a putative mechanism for the development of PPCM, it seems plausible that antiviral treatment might be beneficial. There are no data on the use of antiviral medication for treatment of either acute or chronic PPCM. In patients with 
chronic DCM, however, treatment with interferon resulted in the elimination of viral genomes in cardiac tissue and improved LVEF. ${ }^{52}$ Whether or not antiviral therapy has a beneficial effect in patients with chronic PPCM and persistent viral genomes remains to be tested.

\section{Bromocriptine}

Several case reports have suggested that the addition of bromocriptine to standard heart failure therapy may be beneficial in patients with acute onset PPCM. ${ }^{42,53-56}$ A recently published proof-of-concept randomized pilot study of PPCM patients with severely reduced LVEF diagnosed within one month of delivery showed that patients treated with bromocriptine had greater recovery of LVEF and decreased mortality compared with patients receiving placebo. ${ }^{37}$ As the use of bromocriptine in the postpartum period is associated with an increased risk of thromboembolism, it is strongly recommended that patients with severely reduced LVEF treated with bromocriptine be anticoagulated. However, the results of those small studies need confirmation by larger randomized studies.

\section{Antiarrhythmic treatment}

Tachyarrhythmias may be treated with appropriate rate control medications. Patients with symptomatic or sustained ventricular tachycardia may require treatment with antiarrhythmic medications. There are no guidelines for implantable cardiac defibrillator (ICD) implantation that are specific for PPCM patients. Decisions regarding ICD implantation for primary or secondary prevention of sudden cardiac death in the acute setting must be carefully considered in the context of the natural history of PPCM, whereby a majority of patients recover $\mathrm{LV}$ function within six months after diagnosis. It would not be unreasonable, however, to consider ICD implantation in patients with persistently reduced LV function despite optimal medical therapy six months or longer after presentation.

\section{Nonpharmacological therapy}

Patients with PPCM, either acute or chronic, should follow a low sodium, fluid-restricted diet. Daily low-intensity exercise is reasonable. The effects of vigorous exercise on patients with PPCM have not been studied, but based on the evidence that myocarditis is a cause of sudden death in young athletes, it seems reasonable to advise PPCM patients to refrain from strenuous physical activity during the first few months after diagnosis.

\section{Duration of therapy}

There is no consensus on the duration of treatment for any of the pharmacological therapies discussed in this paper. Although most PPCM patients who experience normalization of cardiac function do so within the first six months after diagnosis, ${ }^{57}$ a study by Fett and colleagues ${ }^{11}$ demonstrated that some PPCM patients showed continued improvement in LV function up to five years after diagnosis. Given these findings, it is not unreasonable to continue standard heart failure therapy indefinitely in patients with persistently reduced
LVEF. Duration of therapy in patients whose LV function has normalized is unclear. As other therapies, including bromocriptine, are still experimental, optimal duration of treatment with any of these therapies has yet to be elucidated.

\section{LABOUR AND DELIVERY}

Timing and mode of delivery in patients who present with PPCM during pregnancy are important issues. These issues should be assessed by the team of care-givers who optimally would include a cardiologist, obstetrician and anesthesiologist, and should be discussed with the woman or couple. Timing of delivery in PPCM patients has not been systematically studied, but it seems reasonable for haemodynamically unstable patients to undergo early delivery before their cardiovascular status deteriorates even further. Planned caesarean section is likely the preferred mode of delivery in these patients in order to prevent the significant haemodynamic stress of labour and vaginal delivery. If the mother is clinically stable, there is no need for early delivery and spontaneous labour is acceptable. Low forceps or vacuum-assisted delivery should be considered if the second stage of delivery is prolonged in order to reduce the exertion of pushing that may result in an acute heart failure exacerbation.

Labour and delivery are best conducted in centres with special expertise in managing pregnancies in women with cardiac disease. Continuous haemodynamic monitoring is not necessary in every case, but may be helpful in patients whose volume status is unclear or fluctuating. Strict monitoring of fluid status is essential, as administration of intravenous fluids may result in pulmonary oedema. Guidelines for anaesthetic management have not been developed. Spinal, epidural and combined spinal epidural anaesthesia techniques have all been used in PPCM patients during either vaginal or caesarean delivery and there is no clear evidence as to which of these techniques is preferred. Thromboprophylaxis with sequential compression devices should be considered.

After delivery, fluids from the lower limbs and contracted uterus are reabsorbed, potentially causing a significant increase in preload. A single dose of intravenous furosemide is frequently administered at this stage. If used during pregnancy for prevention of thromboembolism, anticoagulation with heparin may be restarted following delivery when deemed acceptable by the obstetrician and anaesthesiologist. Cardiology follow-up one to two week post delivery for assessment of cardiovascular status and adjustment of medications and other treatments is recommended.

Due to the high risk for cardiovascular complications, including haemodynamic instability, severe acute heart failure resulting in pulmonary oedema and respiratory compromise, and thromboembolic events, patients should be carefully monitored in an intensive care unit setting for a minimum of 24 hours after delivery. Afterload reduction with ACE inhibitors and nitrates may safely be administered as necessary. Beta blockers may be continued if the patient was previously on a stable dose, but should not be initiated in a beta-blocker naïve patient until acute heart failure symptoms have resolved.

\section{BREASTFEEDING}

Breastfeeding should be discouraged due to the proposed negative effects of $16 \mathrm{kDa}$ prolactin fragments described above. If 
the woman desires to breastfeed despite appropriate counselling about the potential detrimental cardiac effects, standard heart failure medications including beta blockers, ACE inhibitors, ARBs, digoxin and aldosterone antagonists can safely be used. Anticoagulation with warfarin, unfractionated heparin or low molecular weight heparin is compatible with breastfeeding.

\section{PROGNOSIS}

Patients with PPCM have a higher rate of spontaneous recovery of LV function compared with patients with other forms of nonischaemic cardiomyopathy. The proportion of PPCM patients in whom LV function normalizes is estimated to be between $23-54 \%$. $^{11,15,17,23}$

Mortality data are available from studies of PPCM patients in Haiti, Turkey, India, South Africa and the USA. Reported mortality rate varies considerably, ranging from $1.4 \%$ to $30 \%{ }^{5-7,11,14,15,17,24,30,33,58,59}$ In the studies which reported duration of follow-up, mean follow-up ranged from six months to five years.

Various factors predicting morbidity and mortality, including older age at diagnosis, being of African descent, multiparity, increased LV size and decreased LVEF at diagnosis, have been proposed but not validated. Other factors of interest include New York Heart Association class, QRS duration and late onset of symptoms. Further study is necessary in order to determine which, if any, of these may be independent predictors of mortality.

\section{SUBSEQUENT PREGNANCY}

Family planning counselling is essential in women with PPCM, as it is not uncommon for cardiomyopathy to recur with subsequent pregnancies. Information regarding this issue is sparse and most of the data are retrospective, so it is difficult to quantify the risk for an individual patient. In a retrospective study of PPCM patients in the USA by Elkayam et al., ${ }^{60}$ a subset of 44 patients had a total of 60 subsequent pregnancies. Among these 44 patients, LVEF had normalized after the index pregnancy in 28 and remained depressed in 16. All 44 women experienced a reduction in their LVEF with subsequent pregnancy. Heart failure symptoms were more common in women whose LV function had not normalized prior to subsequent pregnancy (44\% versus $21 \%$ ). None of the women whose LVEF had normalized died, while three $(19 \%)$ of women with persistently low LVEF died during subsequent pregnancy.

Habli et al. ${ }^{61}$ conducted a single centre retrospective study of 70 patients with PPCM, of whom 37 had subsequent pregnancy. Sixteen of these 37 women terminated the pregnancy, while the remaining 21 women had successful subsequent pregnancy. Nearly one-third of these 37 women with subsequent pregnancy experienced worsening heart failure symptoms irrespective of LVEF at time of diagnosis. Women with an $\mathrm{LVEF} \leq 25 \%$ at diagnosis had poorer long-term outcome and greater need for cardiac transplantation.

In a prospective study of 56 PPCM patients in India by Mishra et al., ${ }^{62}$ nine of these patients had subsequent pregnancy. Five $(55 \%)$ of these nine patients died, two during pregnancy and three during the postpartum period.

Given these data, all PPCM patients should be counselled regarding risk of worsening cardiac function and even death with subsequent pregnancy. Patients with an LVEF $\leq 25 \%$ at diagnosis and/or whose LVEF has not normalized seem to be particularly at high risk and should be strongly advised against a subsequent pregnancy.

\section{CONTRACEPTION}

Contraceptive counselling in patients with PPCM is critical due to the significant risk of relapse with subsequent pregnancy as outlined above. Oral contraceptives which include oestrogen should be avoided due to the increased risk of thromboembolism. Intramuscular, subcutaneous and subdermal forms of progesterone appear to be both safe and effective. Intrauterine devices have a low failure rate, are long-lasting and do not increase the risk of thromboembolism. Barrier methods of contraception should be avoided due to high failure rate. Sterilization procedures, particularly tubal ligation and insertion of intratubal stents, could be considered. Vasectomy is another option, although this obviously would not be effective if the woman changed partners during her reproductive years.

\section{SUMMARY AND FUTURE DIRECTIONS}

Peripartum cardiomyopathy is a disease which affects women in their last months of pregnancy or during their first months after delivery, often with devastating consequences, including death. The recent specific pathophysiological hypothesis which states that the oxidative stress-Cathepsin D-16 kDa prolactin cascade plays a key role in the development of PPCM in experimental models and in humans suggests that a novel therapeutic approach involving blockade of this pathway with bromocriptine may provide benefit to patients with PPCM. Despite ongoing research, numerous uncertainties regarding the incidence, pathophysiology, treatment and prognosis of patients with PPCM remain and indicate the need for further investigation.

Because PPCM is an uncommon disease in many regions of the world, the establishment of national and international registries to collect prospective clinical data is recommended. Multicentre studies are also needed to further elucidate the pathophysiology of this disease in order to identify potential treatment strategies directed toward pathway-specific targets. Further investigation of genomic profiles of PPCM patients may lead to the identification of specific profiles that increase susceptibility or predict outcome in these patients. Large randomized controlled trials are necessary to evaluate therapeutic interventions, including bromocriptine.

\section{REFERENCES}

1 Demakis JG, Rahimtoola SH, Sutton GC, et al. Natural course of peripartum cardiomyopathy. Circulation 1971;44:1053-61

2 Pearson GD, Veille JC, Rahimtoola S, et al. Peripartum cardiomyopathy: National Heart, Lung, and Blood Institute and Office of Rare Diseases (National Institutes of Health) workshop recommendations and review. JAMA 2000;283:1183-8

3 Sliwa K, Hilfiker-Kleiner D, Petrie MC, et al. Current state of knowledge on aetiology, diagnosis, management, and therapy of peripartum cardiomyopathy: a position statement from the Heart Failure Association of the European Society of Cardiology Working Group on Peripartum Cardiomyopathy. Eur J Heart Fail 2010;12:767-78

4 Kuklina EV, Callaghan WM. Cardiomyopathy and other myocardial disorders among hospitalizations for pregnancy in the United States: 2004-2006. Obstet Gynecol 2010;115:93-100 
5 Mielniczuk LM, Williams K, Davis DR, et al. Frequency of peripartum cardiomyopathy. Am J Cardiol 2006;97:1765-8

6 Brar SS, Khan SS, Sandhu GK, et al. Incidence, mortality, and racial differences in peripartum cardiomyopathy. Am J Cardiol 2007;100:302-4

7 Chapa JB, Heiberger HB, Weinert L, Decara J, Lang RM, Hibbard JU. Prognostic value of echocardiography in peripartum cardiomyopathy. Obstet Gynecol 2005;105:1303-8

8 Witlin AG, Mabie WC, Sibai BM. Peripartum cardiomyopathy: an ominous diagnosis. Am J Obstet Gynecol 1997;176:182-8

9 Pandit V, Shetty S, Kumar A, Sagir A. Incidence and outcome of peripartum cardiomyopathy from a tertiary hospital in South India. Trop Doct 2009;39:168-9

10 Hasan JA, Qureshi A, Ramejo BB, Kamran A. Peripartum cardiomyopathy characteristics and outcome in a tertiary care hospital. J Pak Med Assoc 2010;60:377-80

11 Fett JD, Christie LG, Carraway RD, Murphy JG. Five-year prospective study of the incidence and prognosis of peripartum cardiomyopathy at a single institution. Mayo Clin Proc 2005;80:1602-6

12 Goland S, Modi K, Bitar F, et al. Clinical profile and predictors of complications in peripartum cardiomyopathy. J Card Fail 2009;15:645-50

13 Diao M, Diop IB, Kane A, et al. Electrocardiographic recording of long duration (Holter) of 24 hours during idiopathic cardiomyopathy of the peripartum. Arch Mal Coeur Vaiss 2004;97:25-30

14 Desai D, Moodley J, Naidoo D. Peripartum cardiomyopathy: experiences at King Edward VIII Hospital, Durban, South Africa and a review of the literature. Trop Doct 1995;25:118-23

15 Duran N, Gunes H, Duran I, Biteker M, Ozkan M. Predictors of prognosis in patients with peripartum cardiomyopathy. Int J Gynaecol Obstet 2008;101:137-40

16 Abdel-Qadir HM, Tu JV, Austin PC, Wang JT, Lee DS. Bundle branch block patterns and long-term outcomes in heart failure. Int J Cardiol 2011;146: $213-8$

17 Sliwa K, Forster O, Libhaber E, et al. Peripartum cardiomyopathy: inflammatory markers as predictors of outcome in 100 prospectively studied patients. Eur Heart J 2006;27:441-6

18 Forster O, Hilfiker-Kleiner D, Ansari AA, et al. Reversal of IFN-gamma, oxLDL and prolactin serum levels correlate with clinical improvement in patients with peripartum cardiomyopathy. Eur J Heart Fail 2008;10:861-8

19 Mendes LA, Dec GW, Picard MH, Palacios IF, Newell J, Davidoff R. Right ventricular dysfunction: an independent predictor of adverse outcome in patients with myocarditis. Am Heart J 1994;128:301-7

20 Srichai MB, Junor C, Rodriguez LL, et al. Clinical, imaging, and pathological characteristics of left ventricular thrombus: a comparison of contrast-enhanced magnetic resonance imaging, transthoracic echocardiography, and transesophageal echocardiography with surgical or pathological validation. Am Heart J 2006;152:75-84

21 Friedrich MG, Sechtem U, Schulz-Menger J, et al. Cardiovascular magnetic resonance in myocarditis: A JACC White Paper. J Am Coll Cardiol 2009;53:1475-87

22 Holzmann M, Nicko A, Kuhl U, et al. Complication rate of right ventricular endomyocardial biopsy via the femoral approach: a retrospective and prospective study analyzing 3048 diagnostic procedures over an 11-year period. Circulation 2008;118:1722-8

23 Elkayam U, Akhter MW, Singh H, et al. Pregnancy-associated cardiomyopathy: clinical characteristics and a comparison between early and late presentation. Circulation 2005;111:2050-5

24 Modi KA, Illum S, Jariatul K, Caldito G, Reddy PC. Poor outcome of indigent patients with peripartum cardiomyopathy in the United States. Am J Obstet Gynecol 2009;201:e1-5

25 Melvin KR, Richardson PJ, Olsen EG, Daly K, Jackson G. Peripartum cardiomyopathy due to myocarditis. N Engl J Med 1982;307:731-4

26 Sanderson JE, Olsen EG, Gatei D. Peripartum heart disease: an endomyocardial biopsy study. Br Heart J 1986;56:285-91

27 O'Connell JB, Costanzo-Nordin MR, Subramanian R, et al. Peripartum cardiomyopathy: clinical, hemodynamic, histologic and prognostic characteristics. J Am Coll Cardiol 1986;8:52-6

28 Midei MG, DeMent SH, Feldman AM, Hutchins GM, Baughman KL. Peripartum myocarditis and cardiomyopathy. Circulation 1990;81:922-8

29 Rizeq MN, Rickenbacher PR, Fowler MB, Billingham ME. Incidence of myocarditis in peripartum cardiomyopathy. Am J Cardiol 1994;74:474-7

30 Felker GM, Thompson RE, Hare JM, et al. Underlying causes and long-term survival in patients with initially unexplained cardiomyopathy. $N$ Engl J Med 2000;342:1077-84

31 Bultmann BD, Klingel K, Nabauer M, Wallwiener D, Kandolf R. High prevalence of viral genomes and inflammation in peripartum cardiomyopathy. Am J Obstet Gynecol 2005;193:363-5
32 Kuhl U, Pauschinger M, Seeberg B, et al. Viral persistence in the myocardium is associated with progressive cardiac dysfunction. Circulation 2005;112:1965-70

33 Sliwa K, Skudicky D, Bergemann A, Candy G, Puren A, Sareli P. Peripartum cardiomyopathy: analysis of clinical outcome, left ventricular function, plasma levels of cytokines and Fas/APO-1. J Am Coll Cardiol 2000;35:701-5

34 Ansari AA, Fett JD, Carraway RE, Mayne AE, Onlamoon N, Sundstrom JB. Autoimmune mechanisms as the basis for human peripartum cardiomyopathy. Clin Rev Allergy Immunol 2002;23:301-24

35 Hilfiker-Kleiner D, Kaminski K, Podewski E, et al. A cathepsin D-cleaved $16 \mathrm{kDa}$ form of prolactin mediates postpartum cardiomyopathy. Cell 2007;128:589-600

36 Toescu V, Nuttall SL, Martin U, Kendall MJ, Dunne F. Oxidative stress and normal pregnancy. Clin Endocrinol (Oxf) 2002;57:609-13

37 Sliwa K, Blauwet L, Tibazarwa K, et al. Evaluation of bromocriptine in the treatment of acute severe peripartum cardiomyopathy: a proof-of-concept pilot study. Circulation 2010;121:1465-73

38 Pierce JA, Price BO, Joyce JW. Familial occurrence of postpartal heart failure. Arch Intern Med 1963;111:651-5

39 Massad LS, Reiss CK, Mutch DG, Haskel EJ. Familial peripartum cardiomyopathy after molar pregnancy. Obstet Gynecol 1993;81:886-8

40 Pearl W. Familial occurrence of peripartum cardiomyopathy. Am Heart J 1995;129:421-2

41 Fett JD, Sundstrom BJ, Etta King M, Ansari AA. Mother-daughter peripartum cardiomyopathy. Int J Cardiol 2002;86:331-2

42 Meyer GP, Labidi S, Podewski E, Sliwa K, Drexler H, Hilfiker-Kleiner D. Bromocriptine treatment associated with recovery from peripartum cardiomyopathy in siblings: two case reports. J Med Case Rep 2010;4:80

43 Morales A, Painter T, Li R, et al. Rare variant mutations in pregnancyassociated or peripartum cardiomyopathy. Circulation 2010;121:2176-82

44 van Spaendonck-Zwarts KY, van Tintelen JP, van Veldhuisen DJ, et al. Peripartum cardiomyopathy as a part of familial dilated cardiomyopathy. Circulation 2010;121:2169-75

45 Keogh A, Macdonald P, Spratt P, Marshman D, Larbalestier R, Kaan A. Outcome in peripartum cardiomyopathy after heart transplantation. J Heart Lung Transpl 1994;13:202-7

46 Wojnicz R, Nowalany-Kozielska E, Wojciechowska C, et al. Randomized, placebo-controlled study for immunosuppressive treatment of inflammatory dilated cardiomyopathy: two-year follow-up results. Circulation 2001;104:39-45

47 Frustaci A, Chimenti C, Calabrese F, Pieroni M, Thiene G, Maseri A. Immunosuppressive therapy for active lymphocytic myocarditis: virological and immunologic profile of responders versus nonresponders. Circulation 2003;107:857-63

48 Frustaci A, Russo MA, Chimenti C. Randomized study on the efficacy of immunosuppressive therapy in patients with virus-negative inflammatory cardiomyopathy: the TIMIC study. Eur Heart J 2009;30:1995-2002

49 Sliwa K, Skudicky D, Candy G, Bergemann A, Hopley M, Sareli P. The addition of pentoxifylline to conventional therapy improves outcome in patients with peripartum cardiomyopathy. Eur J Heart Fail 2002;4:305-9

50 Bozkurt B, Villaneuva FS, Holubkov R, et al. Intravenous immune globulin in the therapy of peripartum cardiomyopathy. J Am Coll Cardiol 1999;34:177-80

51 Muroya T, Ikeda S, Yamasa T, et al. High dose immune globulin therapy ameliorates peripartum cardiomyopathy with elevated serum antibody titer to influenza virus: case report of two patients. Med Sci Monit 2010;16:CS11-4

52 Kuhl U, Pauschinger M, Schwimmbeck PL, et al. Interferon-beta treatment eliminates cardiotropic viruses and improves left ventricular function in patients with myocardial persistence of viral genomes and left ventricular dysfunction. Circulation 2003;107:2793-8

53 Hilfiker-Kleiner D, Meyer GP, Schieffer E, et al. Recovery from postpartum cardiomyopathy in 2 patients by blocking prolactin release with bromocriptine. I Am Coll Cardiol 2007;50:2354-5

54 Habedank D, Kuhnle Y, Elgeti T, Dudenhausen JW, Haverkamp W, Dietz R. Recovery from peripartum cardiomyopathy after treatment with bromocriptine. Eur J Heart Fail 2008;10:1149-51

55 Jahns BG, Stein W, Hilfiker-Kleiner D, Pieske B, Emons G. Peripartum cardiomyopathy - a new treatment option by inhibition of prolactin secretion. Am J Obstet Gynecol 2008;199:e5-6

56 Abe T, Amano I, Sawa R, Akira S, Nakai A, Takeshita T. Recovery from peripartum cardiomyopathy in a Japanese woman after administration of bromocriptine as a new treatment option. J Nippon Med Sch 2010;77:226-30

57 Rasmusson KD, Stehlik J, Brown RN, et al. Long-term outcomes of cardiac transplantation for peri-partum cardiomyopathy: a multiinstitutional analysis. J Heart Lung Transpl 2007;26:1097-104 
58 Sliwa K, Forster O, Tibazarwa K, et al. Long-term outcome of peripartum cardiomyopathy in a population with high seropositivity for human immunodeficiency virus. Int J Cardiol 2009; Sep 12 [Epub ahead of print]

59 Fett JD, Carraway RD, Dowell DL, King ME, Pierre R. Peripartum cardiomyopathy in the Hospital Albert Schweitzer District of Haiti. Am J Obstet Gynecol 2002;186:1005-10

60 Elkayam U, Tummala PP, Rao K, et al. Maternal and fetal outcomes of subsequent pregnancies in women with peripartum cardiomyopathy. N Engl J Med 2001;344:1567-71

61 Habli M, O'Brien T, Nowack E, Khoury S, Barton JR, Sibai B. Peripartum cardiomyopathy: prognostic factors for long-term maternal outcome. Am J Obstet Gynecol 2008;199:e1-5
62 Mishra TK, Swain S, Routray SN. Peripartum cardiomyopathy. Int J Gynaecol Obstet 2006;95:104-9

63 Maron BJ, Towbin JA, Thiene G, et al. Contemporary definitions and classification of the cardiomyopathies: an American Heart Association Scientific Statement from the Council on Clinical Cardiology, Heart Failure and Transplantation Committee; Quality of Care and Outcomes Research and Functional Genomics and Translational Biology Interdisciplinary Working Groups; and Council on Epidemiology and Prevention. Circulation 2006;113:1807-16. 